\title{
REVITALIZACIJA PINOVE VILE U VELIKOM BEČKEREKU, DANAŠNJEM ZRENJANINU
}

\section{REVITALIZATION OF THE PINOVA VILLA IN VELIKI BECKEREK, TODAY'S ZRENJANIN}

\author{
Lea Muhi, Fakultet tehničkih nauka, Novi Sad
}

\section{Oblast - ARHITEKTURA - DIZAJN ENTERIJERA}

Kratak sadržaj - Tema ovog rada jeste revitalizacija Pinove vile u Zrenjaninu, i njena prenamena u objekat javnog karaktera. Vila se nalazi na atraktivnoj lokaciji blizu samog centra grada, nova namena koja joj se dodeljuje je zajednički prostor za rad i usavršavanje mladih kreativnih ljudi. Objekat je vrlo inspirativan, kako zbog svojih stilskih karakteristika, tako i zbog činjenice da je jedino izvedeno delo u Vojvodini uglednog Peštanskog arhitekte, profesora $i$ jednog od prvih konzervatora Lasla Đaluša. U ovom slučaju, kao i mnogim drugim kod zanemarenih kulturnih dobara, potrebno je uspostaviti strategiju za očuvanje $i$ zaštitu kulturnog nasleđa što podrazumeva uspostavljanje održivih i relano ostvarivih ciljeva u pogledu revitalizacije, implementacije $i$ prenamene objekata. U teorijskom delu rada analizirano je postojeće stanje objekta, njegove stilske karakteristike, istorijski $i$ društveno- ekonomski kontekst, kao i potrebne metode tehničke mere zaštite spomenika kulture. Studijom slučaja obuhvaćeni su objekti koji su prošli kroz proces transformacije i kojima je revitalizacijom udahnut novi život. Grafički deo rada obuhvata predlog mogućeg funkcionalnog rešenja uz prostorne prikaze odabranih funkcionalnih celina kao uglednih primeraka procesa revitalizacije.

Ključne reči: revitalizacija, Pinova vila, Zrenjanin, zajednički radni prostor

Abstract - The topic of this paper is the revitalization of the Pinova villa in Zrenjanin, and its transformation to a public building. The villa is located in an attractive location close to the city center, a new purpose that is assigned to it is a coworking space for working and perfecting young creative people. The building is very inspiring, because of its stylistic characteristics, and because of the fact that it is the only building in Vojvodina of a renowned architect, a professor and one of the first conservators Laslo Đaluš. In this case, as with many other neglected cultural heritage, it is necessary to establish a strategy for the preservation and protection of cultural heritage, which implies the establishment of sustainable and relatively achievable goals in terms of revitalization, implementation and conversion of facilities. The theoretical part of the theses analyzes the existing condition of the building, its stylistic characteristics, the historical and socio-economic context, as well as the necessary methods of technical measures for the protection of cultural

\section{NAPOMENA:}

Ovaj rad proistekao je iz master rada čiji mentor je bila dr Mirjana Sladić, docent. monuments. The case study includes buildings that have undergone a transformation and revitalization process. The graphical part of the paper includes a proposal for a possible functional solution with $3 D$ visualizations.

Key words: revitalization, Pins villa, Zrenjanin, coworking

\section{UVOD}

\subsection{Predmet istraživanja}

Predmet ovog istraživanja jeste Pinova vila u Zrenjaninu, koja se nalazi u širem centru grada.

Projektovana je i izgrađena kao ugaoni slobodnostojeći stambeni objekat, uvučen u odnosu na regulacionu liniju, koji se nesrećnom urbanističkom intervencijom osamdesetih godina našao na uglu triju ulica, Bulevara Milutina Milankovića (magistrala), ulice Ive Lole Ribara i Jovana Cvijića.

Po svojoj lepoti i raskoši se izdvaja u odnosu na ostale kuće u ovom delu naselja. Vila se prostire na oko $500 \mathrm{~m}^{2}$. Iako je promenila veliki broj vlasnika, ostala je upamćena po svom šestom vlasniku geometru Paji Pinu.

Podignuta je 1894. godine. Vlasnik i naručilac bio je Leon Štegervald, a izgrađena je po planovima uglednog Peštanskog arhitekte, profesora i jednog od prvih konzervatora Lasla Đaluša, ujedno je ovo i jedini njegov objekat u Velikom Bečkereku.

\subsection{Cilj istraživanja}

Ono čemu trebamo da težimo kao društvo, i koji je, po mom mišljenju, jedan od gorućih problema, je upravo promena svesti o kulturnom nasleđu i aktuelizovanje pitanja zanemarivanja kulturnog nasleđa širom gradova Vojvodine, pa i Srbije. Kada budemo razumeli svoju istoriju, svoje kulturno nasleđe i njen značaj, znaćemo da cenimo svoju okolinu.

Ono što je najvažnije što bi trebalo da razumemo u ovom problemu zanemarivanja i zapuštanja zgrada jeste nedostatak komunikacije i razumevanja potreba ljudi, pa prema tome revitalizaciju treba sprovoditi pažljivo, i težiti balansu između potreba ljudi i ciljeva revitalizacije.

Ukoliko želimo da naši gradovi budu humano orijentisani, sa karakteristikama koje ih čine atraktivnim i čine život $\mathrm{u}$ njemu ugodnim, da budu ,pogodni za život“ (eng. Livable city ), shvatamo da je svakako revitalizacija urbanog tkiva grada, i njegovih delova, od izuzetnog značaja za dalji razvoj, ali i edukacija stanovništa o značaju kolektivne memorije, odnosno memorije mesta, kao i značaju kulturnih dobara za identitet grada. 


\section{TEMA I SADRŽAJ RADA}

Rad je strukturno podeljen na istraživački deo i grafički deo.

Istraživački deo obuhvata:

- Istorijski i društveno - ekonomski kontekst nastanka

Pinove vile;

- Osvrt kroz istoriju namene objekta;

- Analizu postojećeg stanja koja obuhvata urbanistički kontekst i lokaciju, prostornu organizaciju, stilkske karakteristike objekta i elemenata i analizu oštećenja;

- Osvrt na konzervatorsko restauratorski projekat obnove fasada na objektu „Pinova vila“ u Zrenjaninu ${ }^{1}$;

- Objašnjenje fenomena zajedničkih radnih prostora (eng. coworking prostora) i razloga njihove popularizacije;

- Studija slučaja kojom su obuhvaćeni i analizirani revitalizovani prostori $\mathrm{i}$ objekti, i njihova prenamena $\mathrm{u}$ zajedničke radne prostore;

- Početni stavovi i ciljevi revitalizacije;

- Arhitektonska analiza idejnog rešenja koja obuhvata potrebne intervencije na postojećem objektu, koncept oblikovanja prostora i odabranih funkcionalnih celina, opis konstrukcije i materijalizacije, instalacije objekta.

Grafički deo rada obuhvata grafičke crteže postojećeg stanja objekta, kao i grafičke crteže idejnog rešenja promene namene i odabranih funkcionalnih celina $\mathrm{i}$ njihove 3D vizuelizacije.

\subsection{Istorijski i društveno- ekonomski kontekst}

U Vojvodini krajem XIX i početkom XX veka dolazi do urbanizacije, industrijalizacije i modernizacije u svakom smislu. Za ovo vremensko razdoblje je karakteristično da postoje istovremeno dva suprotna kulturna obrasca sprski patrijarhat i novi obrazac koji je prihvaćen je evropski obrazac, tada vojvođanski gradovi sve više liče na srednjoevropske. Metropole koje su imale najviše uticaja na dešavanja u Vojvodini su Beč i Budimpešta. Povećanje broja stanovnika u gradovima rezultira nastajanje velikih društvenih promena koje su dovele do formiranja građanskog društva. Pojava građanske klase, koju su činili trgovci, zanatlije, činovnici i drugi, ima uticaj, osim na kulturni život, na građenje rezidencijalnih objekata naročito u centralnom delu grada. U skladu sa tim izgrađena je i Pinova vila kao statusni simbol jedne porodice. Njena uloga, osim za stanovanje je bila i primanje gostiju, priređivanje zabava i sl., pa iz toga sledi broj prostorija u vili, a obrada enterijera je imala jedino ulogu da ostavi utisak gospodstvenosti.

Pripadnicima ovog društvenog poretka postaje dostupno kvalitetno obrazovanje, posebno u inostranstvu, kao i česta putovanja vezana za poslove, školovanje, lečenje ali i u turističke svrhe. Čestom putovanju je doprineo razvoj saobraćaja, odnosno pojava železnice koja je u Veliki Bečkerek uvedena 1883. godine. [1] Pojava železničke pruge je bitno uticala na pravce prostornog razvoja grada. Kao eksterni faktor privrednog razvoja, doprinela je da se privredna preduzeća razvijaju po gotovo celoj periferiji grada, prateći pravce njenog pružanja. [2]

\subsection{Analiza postojećeg stanja}

Kao što je već rečeno, vila je izgrađena kao ugaoni slobodnostojeći stambeni objekat uvučen u odnosu na regulacionu liniju, sastoji se iz suterena, prizemlja, sprata

\footnotetext{
${ }^{1}$ Projekat ustupio Zavod za zaštitu spomenika kulture Zrenjanin
}

i tavana. S obzirom na stanje u kome se trenutno nalazi nije bilo moguće dublje zaći u suteren ali se u njemu nalazila kotlarnica i sastoji se iz nekoliko prostorija. Prizemlje i sprat su stambenog karaktera, dok je tavan nepristupačan.

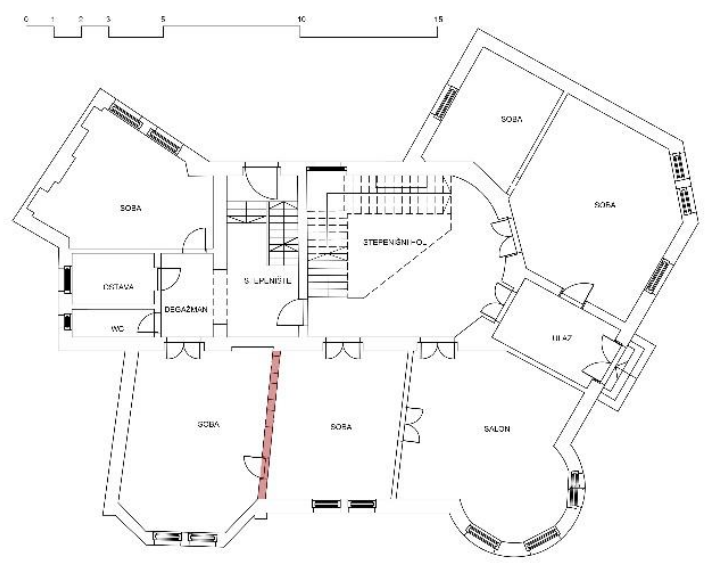

Slika 1 - osnova prizemlja

U osnovi sagledavamo da su sobe galerijski raspoređene oko opslužujućih prostorija, za razliku od dvoraca koji su građeni $u$ istom periodu gde se ova podela ostvaruje podužno dugačkim koridorom. Glavni ulaz u objekat vodi u malo predsoblje iz kog se ulazi u glavni ulazni hol i sobu sa desne strane. U glavnom ulaznom holu se nalazilo raskošno drveno stepenište koje je vodilo na sprat. Ispod stepenišnog kraka se nalazila kaljeva peć koja je bila izrađena od zelene keramike.

Glavni ulazni hol vodi u sve rezidencijalne prostore koje su koristili vlasnici, sobe i salon. Zid koji deli dve sobe levo od salona, obeležen na osnovi crvenom bojom, je dograđen što se vidi po materijalu i načinu građenja. Salon i soba su međusobno povezani vratima što omogućava i direktnu i kružnu komunikaciju. Iz glavnog ulaznog hola se još pristupa stepenišnom prostoru koji ima izlaz na nekadašnji park/dvorište. Ovo stepenište je koristila posluga, ono vodi u suteren, na sprat i tavan. Stepenišni prostor jasno odvaja prostorije za poslogu od prostorija za vlasnike.

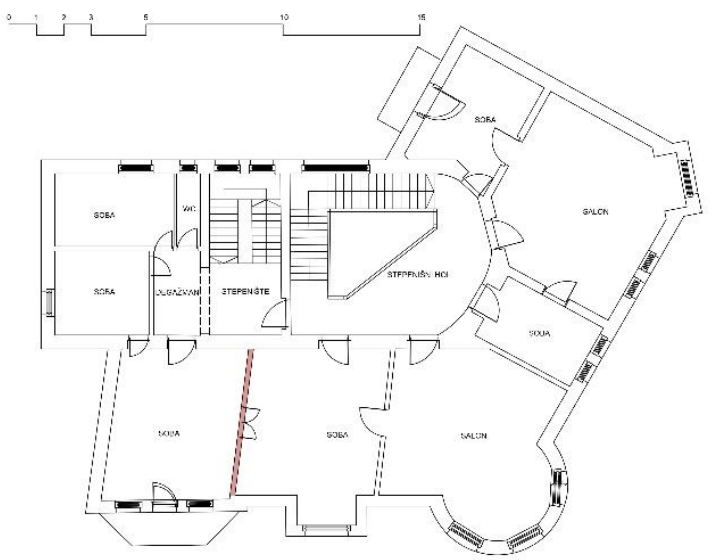

Slika 2 - osnova sprata

$\mathrm{Na}$ sprat se može pristupiti na dva načina: glavnim raskošnim drvenim stepeništem preko galerije ili stepeništem za poslugu. Sa galerije se pristupa svim sobama i salonima. Raspored prostorija je isti kao i u prizemlju, osim što se na spratu nalaze dva salona. Iz stepenišnog prostora za poslugu se pristupa degažmanu, a u ovom delu objekta postoje još dve manje sobe i wc. 
Stil kome ona pripada je eklektika sa elementima romantizma i gotike, što je i karakteristično za kraj XIX veka. Krajem XIX veka su u građanskoj arhitekturi i formalno zavladale eklektičke varijante sa elementima neostilova. Promene se pre svega ogledaju na fasadnim ukrasima i zanatskoj izradi pojedinačnih delova enterijera kao što su prozori, vrata, drvene obloge, kaljeve peći, pa na kraju i nameštaj. Takođe je za kraj XIX veka karakteristično da se prostorije koje su veće pretvaraju u salone, dok se opslužujući sadržaji odvajaju u pomoćne objekte koji se nalaze u sklopu parcele. Na taj način stanovanje biva otmenije i udobnije.

Sasvim je jasno da je stanje u kome se objekat trenutno nalazi i više nego kritično. Građevina je potpuno oronula, čemu oštećenja fasada i krova samo doprinose ulaskom atmosferskih padavina. Svakako da atmosferilije nisu jedini krivac za to, propadanju je doprinelo i zapuštanje objekta, što smatram jednim od glavnih razloga stanja u kome se trenutno nalazi.

\subsection{Savremeni radni prostori}

Coworking (eng.), odnosno zajednički radni prostori se razvijaju još od 90ih godina plošlog veka. Grupa kompjuterskih entuzijasta je 1995. godine pronašla „Cbazu“ u Berlinu. Još tada su postavili trend u hakerskoj zajednici i predstavili fizički, zajednički orijentisani prostor u kome se ljudi sa sličnim interesovanjima mogu okupljati da sarađuju i rade u otvorenom okruženju. Neverovatnim razvojem interneta, koncept rada i poslovanja se u mnogome promenio, što dovodi do pojave honoraraca ili slobodnih radnika (freelancer eng.), koji u određenom trenutku otvaraju pitanje radnog prostora. Paralelno se uz pojavu honoraraca sve više popularizuju zajednički radni prostori. Kada govorimo o ovom konceptu, ne govorimo samo o fizičkim zajedničkim radnim prostorima, već o formiranju zajednice. Praksa upravljanja ovakvih prostora bliža je zadrugama, uključujući fokus na zajednicu, a ne na profit. Dakle, u suštini ovog koncepta je kreiranje ugodnog, neformalnog i kreativnog radnog okruženja za sve koji žele da rade samostalno, ali sa akcentom na formiranje zajednice i isticanjem značaja socijalizacije njenih članova.

Glavni razlozi zbog kojih se ljudi opredeljuju za ovakvu vrstu poslovnog ili radnog prostora je najčešće smanjenje inicijalnih troškova, odnosno početnih ulaganja u prostor i opremu, odvajanje posla od kuće, poboljšanje društvenog života, upoznavanje kolega istih ili sličnih interesovanja, pa samim tim i mogućnost saradnje sa njima, povećanje produktivnosti i slično. Korisnicima je omogućeno da biraju svoje radno vreme i da ga organizuju onako kako njima najviše odgovara, u okruženju koje je inspirativno i produktivno, ali istovremeno fleksibilno i opušteno.

\subsection{Studija slučaja}

Primarni kriterijumi pri odabiru studija slučaja su svakako bili dobri primeri revitalizacije postojećih prostora i objekata, u cilju stvaranja svesti kod ljudi o značaju revitalizacije kao vida očuvanja graditeljskog nasleđa i kolektivne memorije. Osim toga, svaki pojedinačni primer ima svoju jedinstvenu karakteristiku koja je uticala na konačno idejno rešenje. NOVA ISKRA koja daje primer uspešne saradnje mladih kreativnih stručnjaka sa domaćim i stranim kompanijama i proizvođačima. KUĆA U MOKRINU kao jedinstveni primer urbane tačke $u$ ruralnoj okolini, i koja nas podseća koliko nam je neophodno da se okrenemo sebi i prirodi. IMPACT HUB i ROYAL TOWER pokazuju da intervencijama $u$ enterijeru istorijski važnih objekata ne moramo nužno upropastiti postojeće stanje, veštom upotrebom modernih materijala, pažljivim odabirom boja i tekstura se može istaći prvobitna lepota „školjke“ u kome se nalazi novi sadržaj. REPUBLICA 358 dokazuju da spajanjem različitih namena na pravi način možemo pružiti okruženju nezamenljivi deo urbanog života grada koji će predstavljati suštinski urbani identitet tog kraja.

\subsection{Arhitektonska analiza novoprojektovanog idejnog rešenja}

\subsubsection{Koncept oblikovanja prostora}

Ceo objekat Pinove vile je podređen prostorima za zajednički rad sa 20 mesta , i prostorima u kojima mogu da se održavaju seminari, radionice i sl., a koji se po potrebi izdaju, pa je prema tome samoodrživ i plaća sam svoje troškove.

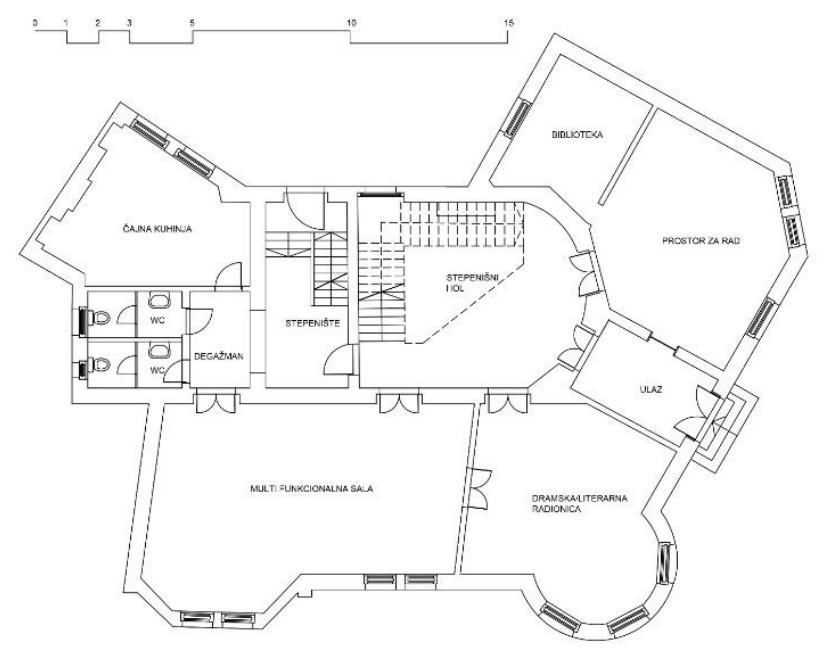

Slika 3 - novoprojektovana osnova prizemlja

Primarni sadržaji u prizemlju orijentisani su oko ulaznog hola. Iz njega se pristupa prostoriji za rad sa 12 mesta za izdavanje sa računarima. Tu se nalazi i prostorija u kojoj se održavaju dramska i literarna sekcija. Takođe se iz ulaznog hola pristupa multi funkcionalnoj sali, koja je opremljena stolicama na rasklapanja i videobimom. Ovaj prostor se nakada sastojao iz dve prostorije podeljene naknadno izgrađenim pregradnim zidom, pa se prema tome ne zadržava. Multifunkcionalna sala se izdaje za održavanje seminara, radionica različitog karaktera i video projekcija. U zadnjem delu objekta, pored opslužujućeg stepeništa su čajna kuhinja i toaleti.

Menadžment i radni prostori su na spratu orijentisani oko drvene galerije stepenišnog hola. Čim se popnete na sprat nailazite prvo na kancelarije upravnika, menadžmenta i organizatora celokupnog sadržaja vile. Sala za sastanke i konferencije je na raspolaganju sa 12 mesta, i iznajmljuje se po potrebi. Sa galerije se još pristupa i zajedničkom radnom prostoru koji je opremljen samo stolovima i stolicama čiji korisnici donose svoja sredstva za rad. Osim radnih prostora, ovde se nalazi i prostor za odmor i druženje, kome se pristupa iz degažmana, opremljen lazy bag-ovima, stonim fudbalom i konzolom za igranja video igrica. Takođe su tu i toaleti i čajna kuhinja. 


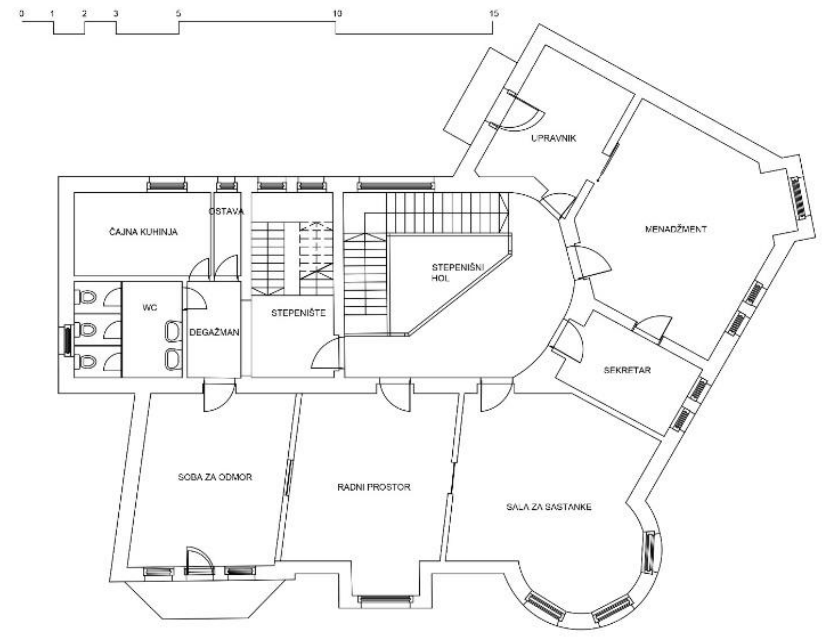

Slika 4 - novoprojektovana osnova sprata

Ukoliko želite da postanete član zajednice, i da iznajmite prostor za rad, potrebno da je da prođete konkurs. Članovi dobijaju mogućnost da rade $u$ inspirativnom okruženju sa kreativnim ljudima. Osim toga, učestvuju u životu vile, u konkursima i radovima koje menadžment organizuje za timski rad, kursevima i seminarima koje ih interesuju, ali takođe sami mogu predložiti neki projekat ili seminar koji ih interesuju, pa na mesečnim sastancima koji se organizuju izglasati njihovu realizaciju.

\subsubsection{Sala za sastanke}

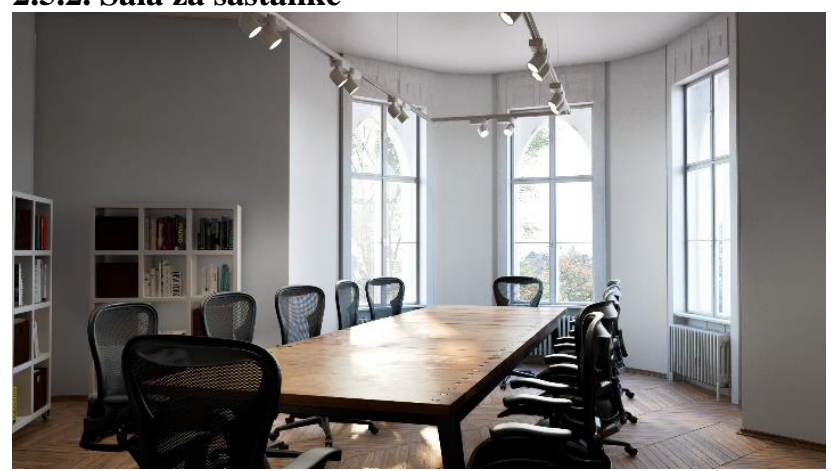

Slika $5-3 \mathrm{D}$ vizuelizacija

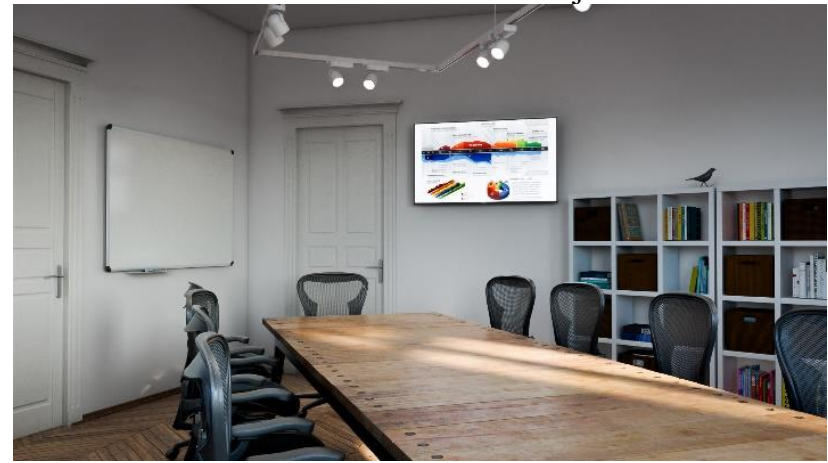

Slika 6 - 3D vizuelizacija

Jedan od tri izabrana prostora koja su detaljno razrađena $\mathrm{u}$ master radu je i sala za sastanke, nalazi se na spratu a pristupa joj se sa galerije. Kako je vila zamišljena kao neformalni prostor namenjen kreativnim mladim ljudima, koji su željni da se iskažu i sarađuju, tako je i enterijer sale za sastanke dizajniran $u$ istom maniru. Neki od intervencija $u$ enterijeru koju su predviđeni su izlivanje cementne košuljice, postavljanje hrastovog parketa, postavljanje elektro instalacija, malterisanje, krečenje, kompletno menjanje prozora, obnavljanje prozorskih maski i maski oko vrata i dodavanje nedostajućih delova. Centralni motiv sale za sastanke je konferencijski sto koji se izrađuje specijalno za ovu prostoriju. Sto je izrađen od čeličnih kutijastih profila, međusobno zavarenih tako da formiraju ram sa 3 podužna profila, gde će se postaviti ploča stola, i 6 nogara. Ploča stola sačinjena je od dasaka koje se šrafe torban šrafovima sa poluokruglom glavom i niskim zaglavkom, sa podloškom i maticom, u čelični ram. Stolice koje su za stolom su Aeron Chair, brenda Herman Miller, ove stolice se nalaze i za svim radnim stolovima. Što se tiče prostora za odlaganje potrebnog kancelarijskog materijala i opreme, ovde se nalaze tri police KALLAX, proizvođača IKEA. Rasveta koja je korišćena u ovoj prostoriji je LED, model SUPERLOOPSPY FOCUS ON MDL, proizvođača Delta Light, koje se nalaze na SUPERLOOP S HC MDL vođicama pravouganog oblika, prateći sto iznad koga se nalaze, istog proizvođača.

\section{ZAKLJUČAK}

Tumačenje termina REVITALIZACIJA danas nema jedinstveno značenje. Osnovno značene je oživljavanje i podrazumeva vraćanje prvobitne funkcije građevinama koje su tu funkciju izgubile i njihovo ponovno vraćanje $u$ život. Revitalizacija se prvenstveno primenjuje na kulturna dobra koja su prestala da se koriste ili im je namena u savremenim uslovima prevaziđena. Zato ovaj pojam ima šire značenje od osnovnog značenja termina $\mathrm{i}$ može se primeniti na sva kulturna dobra kod kojih se moraju rešavati problemi njihove funkcije i potencijala $u$ savremenim uslovima.

Predlog rešenja revitalizacije Pinove vile je pozitivan model mogućeg načina transformacije ovog objekta, koji ima potencijala da postane atraktivnije mesto za okupljanje mladih, kao jedan novi centar za razvoj i usmeravanje kreativnih ljudi u Zrenjaninu. Ovaj objekat bi trebao da doprinese ne samo očuvanju same zgrade, već unapređenju kulturnog nasleđa, njegove važnosti za lokalnu zajednicu i integraciju u svakodnevni život, zaštitu vrednosti i kulturnog identiteta prostora, održivost i ekonomski razvoj.

\section{LITERATURA}

[1] Janjušević, Bogdan: Nastanak i razvoj stambenih palata i vila u Vojvodini oblikovanih u stilu secesije krajem XIX i početkom XX veka, Novi Sad: VOJVOĐANSKA AKADEMIJA NAUKA I UMETNOSTI, Fondacija akademika Bogumila Hrabaka za publikovanje doktorskih disertacija, 2014.

[2] Pušić, Ljubinko: Urbanistički razvoj gradova u Vojvodini u XIX i prvoj polovini XX veka, Novi Sad: Matica Srpska, Odeljenje za društvene nauke, 1987.

\section{Kratka biografija:}

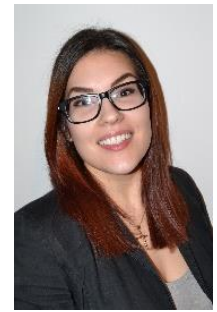

Lea Muhi, rođena u Zrenjaninu 1991 . godine. Bachelor rad na Fakultetu tehničkih nauka u Novom sadu, iz oblasti Arhitekture - Arhitektonsko projektovanje odbranila je 2016. godine i stekla zvanje diplomirani inženjer arhitekture. Master rad na smeru Dizajn enterijera brani 2018. godine. 